\title{
School staff, parent and student perceptions of a Breakfast in the Classroom model during initial implementation
}

\author{
Sara C Folta ${ }^{1}$, Holly Carmichael Diang ${ }^{2}$, Megan Halmo², Nesly Metayer ${ }^{2}$, \\ Stacy A Blondin 1, Kathleen S Smith ${ }^{2}$ and Christina D Economos 1,2,* \\ ${ }^{1}$ Friedman School of Nutrition Science and Policy, Tufts University, 150 Harrison Avenue, Boston, MA 02111 , USA: \\ ${ }^{2}$ ChildObesity 180, Friedman School of Nutrition Science and Policy, Tufts University, Boston, MA, USA
}

Submitted 5 February 2015: Final revision received 15 December 2015: Accepted 17 December 2015: First published online 28 January 2016

\begin{abstract}
Objective: To understand perspectives of stakeholders during initial district-wide implementation of a Breakfast in the Classroom (BIC) model of the School Breakfast Program.

Design: Qualitative data were collected from twenty-nine focus groups and twenty interviews with stakeholders in a school district early in the process of implementing a BIC model of the School Breakfast Program.

Setting: Ten elementary schools within a large, urban school district in the USA that served predominantly low-income, racial/ethnic minority students.

Subjects: Purposively selected stakeholders in elementary schools that had implemented BIC for 3-6 months: students ( $n$ 85), parents/guardians ( $n$ 86), classroom teachers ( $n$ 44), cafeteria managers ( $n$ 10) and principals (n 10).

Results: Four primary themes emerged, which were interpreted based on the Diffusion of Innovations model. School staff had changed their perceptions of both the relative disadvantages and costs related to time and effort of BIC over time; the majority of each stakeholder group expressed an appreciation for BIC; student breakfast consumption varied from day to day, related to compatibility of foods with child preferences; and stakeholders held mixed and various impressions of BIC's potential impacts.

Conclusions: The study underscores the importance of engaging school staff and parents in discussions of BIC programming prior to its initiation to pre-emptively address concerns related to cost, relative disadvantages and compatibility with child preferences and school routines/workflow. Effectively communicating with stakeholders about positive impacts and nutritional value of the meals may improve support for BIC. These findings provide new information to policy makers, districts and practitioners that can be used to improve implementation efforts, model delivery and outcomes.
\end{abstract}

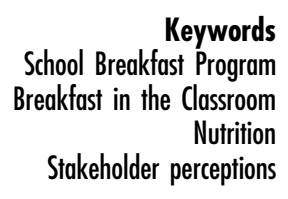

Breakfast consumption among children has been associated with improved diet quality ${ }^{(1-3)}$, physical activity levels $^{(4-6)}$ and school performance ${ }^{(7-9)}$, as well as reduced risk for overweight and obesity ${ }^{(3,4,8,10,11)}$. Yet, approximately $20 \%$ of children in the USA skip breakfast daily ${ }^{(3)}$. The School Breakfast Program (SBP) was established in 1966 to increase breakfast consumption, especially among 'nutritionally needy' school-aged children in the USA, by providing free or reduced-priced morning meals to students ${ }^{(12)}$. Participation in the SBP has been linked with improved adequacy and quality of children's diets ${ }^{(13,14)}$, healthier weight status ${ }^{(15-17)}$ and improved academic performance ${ }^{(7)}$.

Although student participation in the SBP has risen steadily since its inception, the programme remains underutilized $^{(18,19)}$. Traditionally served in the cafeteria before school, timing (parents needing to get children to school earlier, tight school bus schedules) and social stigma have posed barriers to breakfast consumption at school ${ }^{(20-22)}$. Several non-profit advocacy organizations have undertaken initiatives to increase participation by raising awareness about the programme at the district level and by improving the delivery model ${ }^{(23-25)}$. These strategies appear to have had some effect. For example, in the 2013-14 school year, the SBP served approximately 13.2 million children daily, up from 7.5 million in $2000^{(19,26)}$. However, despite steady growth in participation, only half $(53.2 \%)$ of low-income children who participated in the National School Lunch Program also participated in the $\mathrm{SBP}^{(23)}$. This gap between eligibility and participation illustrates a need for more fundamental solutions to improve participation. 
One such solution that is being increasingly adopted, particularly by schools with high proportions of students from low-income households, is the Breakfast in the Classroom (BIC) delivery model. This SBP delivery model makes breakfast available for free to all students in the classroom after the morning bell, thereby mitigating the major barriers related to timing and stigma. Typically BIC takes place at the start of the school day, as the first activity, and lasts $10-15 \mathrm{~min}$. The BIC model has been shown to substantially increase both SBP participation ${ }^{(22,27-30)}$ and breakfast consumption $^{(31)}$ and has been associated with a higher diet quality ${ }^{(32)}$, and may therefore impact students' health and academic performance. If adopted more widely, as expected given current funding and advocacy efforts, BIC has the potential to be an effective approach to improving child nutrition and well-being.

Expansion of BIC has occurred within the last several years and this delivery model has now been implemented in some of the largest school districts in the USA ${ }^{(29)}$. Few studies have documented the perceptions held by parents, teachers, administrators, other school staff and students on this delivery model $^{(27,28,33)}$. In a pilot study, McLaughlin et al. ${ }^{(27)}$ reported that prior to BIC implementation, school staff anticipated that the model would pose challenges, such as loss of preparation and instruction time. However, this concern surfaced only among school staff in schools that had not yet implemented the model; principals and teachers in schools already implementing BIC reported that the breakfast model had little effect on teacher preparation or

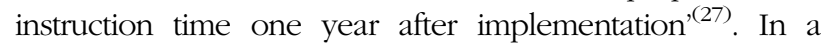
second study, teachers retrospectively characterized BIC six weeks post-intervention as neither messy nor disruptive ${ }^{(28)}$. In both studies, students reported satisfaction with eating breakfast in their classrooms ${ }^{(27,28)}$. Yet despite these initial positive findings of teacher and student perceptions, assessments of the full range of stakeholder groups are needed to understand aspects that promote or hinder adoption of BIC. Stakeholders may hinder or accelerate diffusion by influencing other stakeholders and through their potential impact on implementation ${ }^{(34)}$.

The current study presents perceptions of stakeholders in a large urban school district in the midst of transitioning to a district-wide BIC model of SBP, which allowed for the collection of both retrospective and real-time perspectives from each stakeholder group as the model was being adopted. The aim was to understand stakeholder perceptions during the transition period to provide information on factors that support or hinder diffusion of this model. It extends previous studies by providing perspectives from a broader range of stakeholder groups: parents/guardians (hereafter referred to as 'parents'), teachers, students, principals and cafeteria managers. Understanding multiple perspectives could aid policy makers and school administrators in identifying key supporters, pre-emptively addressing stakeholder concerns and better understanding implementation of BIC overall to facilitate successful adoption of this model.

\section{Methods}

\section{Recruitment and sample}

The present study was conducted with ten elementary schools from a large urban US district during its first year of a district-wide three-year implementation of BIC. All schools in the district had been providing a before-school, universal free breakfast. In the initial year (2012-13), the district launched BIC in approximately half of the elementary schools, those with the highest proportion of students who were eligible for free and reduced-price meals that also had low participation in the SBP. The implementing schools were similar to the rest of the district based on other demographic factors.

Research staff worked closely with district leadership to select a purposive sample of schools. The sampling strategy was designed to include the full range of views based on district variability in socio-economic status, language and geography. Eleven principals were contacted and ten agreed to participate. Key informant interviews were conducted with principals and cafeteria managers representing all ten elementary schools. Five of these principals allowed research staff to recruit teachers, parents and students from their respective schools to participate in focus groups.

In these five schools, teachers were recruited for focus groups by distributing flyers in their mailboxes inviting them to contact research staff if they were interested. Any teachers who responded before the scheduled focus group were included. Parents and students were recruited via flyers (in both English and Spanish) sent home with all students enrolled in kindergarten through fifth grade at the five schools ( $n$ 2923). To maximize convenience and resources, parent/child dyads were recruited together and focus groups for both participant groups were conducted simultaneously. Parents were invited to call a dedicated research telephone line to be screened for inclusion in the study. Eligible parents had to have a child enrolled in the study school, be willing to allow the child to participate in the child focus group, and speak English and/or Spanish. Research staff received 149 calls to the research telephone line from parents. Fifty-one parents did not participate, mainly due to scheduling conflicts, failure to return the researcher's follow-up call and limited group capacity.

All qualitative data were collected in the spring of 2013, after each participating school had experienced the BIC model for 3-6 months. The research team conducted twenty-nine focus groups in total with teachers (five groups, one per school), parents (ten groups, two per school) and students (fourteen groups; three per school at four schools, two groups at one of the schools) and twenty key informant interviews with principals and cafeteria managers, thereby capturing 235 independent voices. Due to the large Spanish-speaking population in the school district, parent focus groups were conducted in English (five groups, forty participants) and Spanish (five groups, forty-six participants). All other focus groups and key informant interviews were conducted in English. 
The study was conducted according to the Declaration of Helsinki guidelines and all procedures involving human subjects were approved by the Tufts University Institutional Review Board. Tufts researchers also followed usual protocol for conducting research in the district, including obtaining approval from the district's research office. Written or verbal informed consent or assent was obtained from all participants. Verbal consent or assent was witnessed and formally recorded.

\section{Instrument development}

Semi-structured focus group and key informant interview guides were created for each participant group. Key topic areas were identified based on prior literature and district context, and the research team brainstormed questions related to each key topic area. Representatives from the school district also provided input on questions of interest to them. Three research team members then formulated specific questions with input from two additional team members with expertise in qualitative methods. The research team refined and reformulated these questions and pilot-tested the instruments with age-appropriate participants (English-speaking only). Sample questions for each participant group are provided in Table 1.

\section{Data collection procedures}

Twenty-one research staff members were recruited and trained on study protocols and processes by two senior researchers. For each group, one research team member moderated the session, another took notes and a third documented observations and impressions of the focus group, such as body language. To adhere to district-specific child protection protocols, a fourth individual, employed by the district, was also present at each student group. Students and their parents were provided with informed consent/assent packets prior to the focus groups and written and verbal consent/assent was obtained at the groups. Parent and student focus groups occurred separately but simultaneously. Generally twice the number of student groups was conducted as parent groups to keep the number of participants appropriately small. Students participated in focus groups

Table 1 Sample interview questions about the Breakfast in the Classroom model of the School Breakfast Program, by respondent group

\begin{tabular}{|c|c|c|c|c|c|}
\hline & Principals & Cafeteria managers & Teachers & Parents & Students \\
\hline Attitudes & $\begin{array}{l}\text { How did you initially } \\
\text { feel about } \\
\text { switching from } \\
\text { serving breakfast } \\
\text { in the cafeteria to } \\
\text { serving it in the } \\
\text { classroom? }\end{array}$ & $\begin{array}{l}\text { How did you initially } \\
\text { feel about } \\
\text { switching from } \\
\text { serving breakfast } \\
\text { in the cafeteria to } \\
\text { serving it in the } \\
\text { classroom? }\end{array}$ & $\begin{array}{l}\text { What do you see as the } \\
\text { most positive aspect } \\
\text { of the breakfast in the } \\
\text { classroom } \\
\text { programme? } \\
\text { What would you change } \\
\text { about the current } \\
\text { breakfast in the } \\
\text { classroom } \\
\text { programme? }\end{array}$ & $\begin{array}{l}\text { What do you think about } \\
\text { the change from } \\
\text { cafeteria breakfast to } \\
\text { classroom breakfast? } \\
\text { To the best of your } \\
\text { knowledge, what does } \\
\text { your child think about } \\
\text { breakfast in the } \\
\text { classroom? }\end{array}$ & $\begin{array}{l}\text { Do you like eating } \\
\text { breakfast in your } \\
\text { classroom? }\end{array}$ \\
\hline Implementation & $\begin{array}{l}\text { What barriers or } \\
\text { challenges have } \\
\text { you encountered in } \\
\text { implementing } \\
\text { breakfast in the } \\
\text { classroom? }\end{array}$ & $\begin{array}{l}\text { What was the biggest } \\
\text { barrier or } \\
\text { challenge you } \\
\text { faced in } \\
\text { implementing } \\
\text { breakfast in the } \\
\text { classroom? }\end{array}$ & $\begin{array}{l}\text { What would help make } \\
\text { breakfast run more } \\
\text { smoothly in your } \\
\text { classroom? }\end{array}$ & $\begin{array}{l}\text { Think about what typically } \\
\text { happens once your child } \\
\text { gets to school. To the } \\
\text { best of your knowledge, } \\
\text { what does your child eat } \\
\text { or drink during breakfast } \\
\text { in the classroom? }\end{array}$ & $\begin{array}{l}\text { Do you eat or drink } \\
\text { anything during } \\
\text { breakfast in the } \\
\text { classroom? } \\
\text { What else do you do } \\
\text { while you are eating } \\
\text { breakfast in the } \\
\text { classroom? }\end{array}$ \\
\hline Effects & $\begin{array}{l}\text { In your opinion, how } \\
\text { have students and } \\
\text { families been } \\
\text { affected by } \\
\text { breakfast in the } \\
\text { classroom? }\end{array}$ & $\begin{array}{l}\text { In your opinion, how } \\
\text { have students and } \\
\text { families been } \\
\text { affected by } \\
\text { breakfast in the } \\
\text { classroom? }\end{array}$ & $\begin{array}{l}\text { Describe any effects, } \\
\text { positive or negative, } \\
\text { that breakfast in the } \\
\text { classroom has had on } \\
\text { your classroom's } \\
\text { morning routine. } \\
\text { Tell us your thoughts } \\
\text { about the effects, both } \\
\text { positive and negative, } \\
\text { of the breakfast in the } \\
\text { classroom model on } \\
\text { your students. }\end{array}$ & $\begin{array}{l}\text { Describe any changes } \\
\text { you've seen in your } \\
\text { child since breakfast in } \\
\text { the classroom started. }\end{array}$ & $\begin{array}{l}\text { How do you feel after } \\
\text { eating breakfast in } \\
\text { the classroom? }\end{array}$ \\
\hline Improvements & $\begin{array}{l}\text { What suggestions } \\
\text { would you make to } \\
\text { improve upon or } \\
\text { enhance the } \\
\text { current breakfast in } \\
\text { the classroom } \\
\text { model? }\end{array}$ & $\begin{array}{l}\text { What suggestions } \\
\text { would you make to } \\
\text { improve upon or } \\
\text { enhance the } \\
\text { current breakfast in } \\
\text { the classroom } \\
\text { model? }\end{array}$ & $\begin{array}{l}\text { What would help make } \\
\text { breakfast run more } \\
\text { smoothly in your } \\
\text { classroom? }\end{array}$ & $\begin{array}{l}\text { What changes, if any, } \\
\text { would you suggest/ } \\
\text { recommend to improve } \\
\text { the breakfast in the } \\
\text { classroom model as a } \\
\text { whole? }\end{array}$ & $\begin{array}{l}\text { If you could wave a } \\
\text { magic wand and } \\
\text { change one thing } \\
\text { about breakfast in } \\
\text { the classroom, what } \\
\text { would you change? }\end{array}$ \\
\hline
\end{tabular}


according to grade level ( $\mathrm{K}-2$ or 3-5) at their respective schools. All adult participants (parents, teachers, principals and cafeteria managers) were asked to complete a questionnaire prior to the discussion or interview to obtain demographic information. Child gender was observed and recorded in the student focus groups by researchers. Focus groups with adults lasted up to $60 \mathrm{~min}$ and those with children lasted up to $45 \mathrm{~min}$. Key informant interviews lasted up to $60 \mathrm{~min}$. Adult focus group participants and key informants received \$US 50 for their participation. Child participants received a small gift (such as a pencil or stickers). All discussions were audio recorded, with the exception of one when the moderator failed to turn the recorder on. Research personnel formally debriefed and documented impressions from each session immediately following the discussion.

\section{Analytical methods}

All audio recordings of focus groups and interviews were transcribed. Recordings from focus groups conducted in Spanish were transcribed in Spanish and the Spanish text was translated into English for analysis. The full analysis team included two senior analysts and four trained research assistants. The senior analysts created a codebook to capture responses directly related to the overarching research questions via line-by-line coding of one transcript from each respondent group. An experienced analyst not involved in data collection efforts coded one transcript from each respondent group to validate the initial codebook. In an inductive thematic coding process ${ }^{(35)}$, additional codes were created as they emerged from the data. The codebook was iteratively refined based on input from the full analysis team. To conduct the coding, inter-rater reliability was tested and established by ensuring $80 \%$ agreement between the two senior researchers, and then by establishing the same degree of agreement among the full team on three randomly chosen transcripts. Each transcript was then coded by one analyst. A senior analyst compared final themes against the notes and observations that were recorded during data collection to validate findings. Trends were assessed across all participants collectively, and across each respondent group independently to enable researchers to draw between-group comparisons. Major themes and subthemes were identified, along with other minor themes. Themes were identified by examining data for patterns while also considering contradictions and negative evidence. Analyses were conducted with the qualitative data analysis software NVivo10 (QSR International, Doncaster, VIC, Australia).

The themes that emerged were then interpreted based on the Diffusion of Innovations model, which posits that the rate and extent of adoption of an innovation are based on specific characteristics of the innovation ${ }^{(36)}$. Although district policy mandated initial adoption of BIC by schools, the characteristics described by the Diffusion of Innovations model also inform the degree of implementation by school personnel directly responsible and therefore whether the BIC innovation will be fully and sustainably incorporated into institutional practices. These characteristics are: cost (including time and effort); relative advantage of the innovation (i.e. BIC) over what is being displaced (the traditional before-school universal breakfast programme); compatibility (with the existing culture, values, routines and practices of the implementing organization); observability (the extent and speed at which the outcomes are apparent to the implementer); and, less relevant in this case, simplicity (the ease of understanding an innovation) and trialability (how easy it is to pilot an innovation prior to full adoption) ${ }^{(37)}$.

\section{Results}

In the study schools, $81 \%$ of the students were Hispanic, $70 \%$ were eligible for free and reduced-price meals (household income $<185 \%$ of the poverty level adjusted for household size), $32 \%$ were English-language learners and $4 \%$ of students were in special education (Table 2). These characteristics were reflective of the overall district.

Table 3 presents characteristics of the adult sample, indicating that the majority of respondents were female, Hispanic and less than 65 years of age. Limited demographic data were collected on the eighty-five student focus group participants. One-third (32.9\%) were in $\mathrm{K}-2$ and two-thirds (67.1\%) were in grades 3-5; $43.5 \%$ of the participating students were male.

Four primary themes emerged: (i) school staff changed their perceptions and practices related to the BIC model over the 3-6 months of implementation; (ii) the majority of each stakeholder group expressed a current general appreciation for BIC; (iii) students' consumption of schoolprovided breakfast varied from day to day based on student and family discretion; and (iv) stakeholders held mixed and various impressions of the model's potential impacts. Representative quotes of the four primary themes are presented in Table 4.

\section{Theme 1: evolution of perception of the Breakfast in the Classroom model and model practice}

The first theme reflected the respondent groups' perspectives on how the BIC model and expectations evolved over the initial implementation period.

Table 2 Sociodemographic characteristics of students at the ten elementary schools, within a large, urban school district in the USA, implementing a Breakfast in the Classroom model of the School Breakfast Program

\begin{tabular}{lcc}
\hline Variable & \% or Mean & SD \\
\hline Hispanic (\%) & 81 & 11 \\
Eligible for free/reduced-price lunch (\%) & 70 & 39 \\
English-language learners (\%) & 32 & 7 \\
In special education (\%) & 4 & 1 \\
Total enrolment (mean) & 514.8 & 197.2 \\
\hline
\end{tabular}


Table 3 Sociodemographic characteristics of adult key informants and focus group participants from the ten elementary schools, within a large, urban school district in the USA, implementing a Breakfast in the Classroom model of the School Breakfast Program

\begin{tabular}{|c|c|c|c|c|c|c|c|c|}
\hline \multirow[b]{2}{*}{ Variable } & \multicolumn{2}{|c|}{ Principals ( $n$ 10) } & \multicolumn{2}{|c|}{ Cafeteria managers $(n 10)$} & \multicolumn{2}{|c|}{ Teachers $(n 44)$} & \multicolumn{2}{|c|}{ Parents ( $n$ 86) } \\
\hline & $n$ or Mean & $\%$ or SD & $n$ or Mean & $\%$ or SD & $n$ or Mean & $\%$ or SD & $n$ or Mean & $\%$ or SD \\
\hline \multicolumn{9}{|l|}{ Age group (\%) } \\
\hline $18-24$ years & 0 & 0 & 0 & 0 & 0 & 0 & $1^{*}$ & 1 \\
\hline $25-44$ years & 5 & 50 & 4 & 40 & 26 & 59 & 65 & 76 \\
\hline $45-64$ years & 5 & 50 & 6 & 60 & 14 & 32 & 18 & 21 \\
\hline $65+$ years & 0 & 0 & 0 & 0 & 4 & 9 & 1 & 1 \\
\hline \multicolumn{9}{|l|}{ Gender (\%) } \\
\hline Female & 6 & 60 & 9 & 90 & 36 & 82 & 78 & 91 \\
\hline \multicolumn{9}{|l|}{ Ethnicity (\%) } \\
\hline Hispanic & 4 & 40 & 9 & 90 & 19 & 43 & $66^{*}$ & 77 \\
\hline \multicolumn{9}{|l|}{ Race (\%) } \\
\hline White & 4 & 40 & 2 & 20 & $26^{*}$ & 59 & $23^{*}$ & 27 \\
\hline Black/African American & 2 & 20 & 1 & 10 & 3 & 7 & 7 & 8 \\
\hline Asian & 0 & 0 & 0 & 0 & 3 & 7 & 4 & 5 \\
\hline Multiracial & 1 & 10 & 0 & 0 & 1 & 2 & 0 & 0 \\
\hline Other & 3 & 30 & 7 & 70 & 10 & 23 & 46 & 53 \\
\hline Years at current school, mean and SD & 3.5 & $2 \cdot 3$ & 4.6 & 4.9 & $11 \cdot 8$ & 5.4 & $\mathrm{~N} / \mathrm{A}$ & \\
\hline
\end{tabular}

N/A, not applicable.

*Some data missing.

School staff (teachers, principals, food-service personnel) The majority of school staff expressed that they had held concerns about BIC prior to its launch. In terms of Diffusion of Innovations, they had anticipated a high cost of time and effort. Specifically, they had expected that an increase in staffing would be necessary to address the increase in breakfast participation resulting from BIC. Teachers recalled apprehension about roles expanding and BIC interfering with instruction. School principals were also concerned about the potential loss of instructional time, implying a relative disadvantage since valued academic outcomes could be jeopardized.

However, at the time of the study (3-6 months post-implementation), the majority of school staff indicated that many of the challenges associated with these concerns had been mitigated. Food-service staff reported that additional, temporary staff had been provided by the district when the model was initially launched, and that they themselves had been able to return to their original workforce once procedures became routinized. Many, but not all teachers reported that their concerns about role expansion had been allayed. In younger grades, parent volunteers were able to assist in the classroom; and in some schools students assisted by bringing food carts to the classroom and by taking care of their own trash. School staff acknowledged that the implementation model had evolved naturally over the months since launch, becoming compatible with existing routines and workflow. Many spoke of BIC as taking on its own rhythm and becoming systematic, running more smoothly than they anticipated it would, both at the school level and the classroom level.

However, initial concerns about the loss of instructional time persisted. While many teachers found ways to incorporate instruction into the breakfast period, making it productive and learning-centric, others did not and remained concerned about reduced learning during this time.

\section{Theme 2: appreciation for the Breakfast in the Classroom model}

Another theme that emerged suggested that perspectives evolved during the months following initial implementation towards recognition of a number of relative advantages of the BIC model.

School staff (teachers, principals, food-service personnel) Teachers and principals indicated that the BIC delivery model had in fact increased cost (in terms of time and effort) by expanding this role beyond traditional instruction, although to a lesser extent than initially anticipated. New tasks included monitoring and mediating consumption, cutting fruit for younger students, auditing participation and supplies, and teaching nutrition and manners. Despite these additional responsibilities, the model was seen as having a relative advantage in terms of impact on students. For example, school staff expressed that students were able to consume breakfast even when late for school, which was either not possible with the traditional before-school model since the cafeteria would have closed; or highly undesirable, because it would require missing additional class time. Some teachers also noted that BIC provided a safer physical and emotional environment than the cafeteria, which involved eating with older children and less adult supervision. They also reported that BIC time, which was often unstructured, helped students establish or strengthen relationships with their classmates. 
Table 4 Sample quotes from stakeholder groups supporting Breakfast in the Classroom (BIC) themes

\begin{tabular}{|c|c|c|c|c|c|}
\hline Theme & Principals & Cafeteria managers & Teachers & Parents & Students \\
\hline Evolution & $\begin{array}{l}\text { 'Again, there was already a } \\
\text { mindset of how it was going to } \\
\text { be, you know, with principals } \\
\text { and teachers. Like, it's going to } \\
\text { be - it's going to be chaos, you } \\
\text { know? Basically, it was an } \\
\text { experiment that was tried and } \\
\text { proved to be the opposite of } \\
\text { what most principals and } \\
\text { teachers thought it was going to } \\
\text { be.' }\end{array}$ & $\begin{array}{l}\text { 'I know it was much easier than we } \\
\text { thought, that's for sure.' }\end{array}$ & $\begin{array}{l}\text { 'There's like a whole system. So it } \\
\text { makes it go faster, it's not taking } \\
\text { as much time as we originally } \\
\text { assumed it was going to take.' }\end{array}$ & $N / A$ & $\mathrm{~N} / \mathrm{A}$ \\
\hline Appreciation & $\begin{array}{l}\text { 'I love walking into my classrooms } \\
\text { and seeing my children all } \\
\text { sitting down and eating their } \\
\text { breakfast, you know, and it's a } \\
\text { beautiful sight. Teachers } \\
\text { reading to them. Some of them } \\
\text { are playing Beethoven music } \\
\text { and asking what sounds do you } \\
\text { hear.' }\end{array}$ & $\begin{array}{l}\text { 'So my thing is l'm just happy that } \\
\text { more kids are able to eat than } \\
\text { before, because of the time they } \\
\text { just couldn't get to school and } \\
\text { couldn't eat in time.' }\end{array}$ & $\begin{array}{l}\text { 'I agree that it's a positive } \\
\text { experience for my kids. And we } \\
\text { use that time in different ways, } \\
\text { and a lot of times it'll just be kind } \\
\text { of me prepping them for the day } \\
\text { ahead while they're enjoying } \\
\text { their meal in the morning. So } \\
\text { overall, it's a very positive } \\
\text { experience.' }\end{array}$ & $\begin{array}{l}\text { 'As a mother, I like what they've } \\
\text { done in the classroom because } \\
\text { there's camaraderie. There's } \\
\text { more trust between the kids and } \\
\text { the teacher. And she sees } \\
\text { everything that goes on and } \\
\text { what they're actually eating.' }\end{array}$ & $\begin{array}{l}\text { 'That was the problem before we } \\
\text { got the BIC, I would go upstairs } \\
\text { [to the cafeteria before school], } \\
\text { but it was closed ... Then you } \\
\text { don't get breakfast, you're going } \\
\text { to be in the classroom starving.' }\end{array}$ \\
\hline Consumption & $\begin{array}{l}\text { 'Like, coffee cake day, I guarantee } \\
\text { you that kids, even if they're not } \\
\text { hungry, they're like, "Oh, I'm } \\
\text { going to [participate]" you know, } \\
\text { it's coffee cake day!' }\end{array}$ & $\begin{array}{l}\text { 'They love the coffee cake. That } \\
\text { day I don't have very much } \\
\text { coming back. On the coffee } \\
\text { cake I give them the full amount } \\
\text { that [the teachers] ask because } \\
\text { I know everybody's going to } \\
\text { eat it.' }\end{array}$ & $\begin{array}{l}\text { 'If it's a burrito, [they're] unlikely to } \\
\text { take it. If it's a weird muffin, or } \\
\text { pumpkin bread that no one dug, } \\
\text { then they're not eating it.' }\end{array}$ & $\begin{array}{l}\text { 'But as far as the food, yeah, } \\
\text { sometimes we look at the menu } \\
\text { and he'll be you know what, I } \\
\text { don't like this. So sometimes I } \\
\text { would still have to cook in the } \\
\text { morning and have him eat at } \\
\text { home.' }\end{array}$ & $\begin{array}{l}\text { 'Sometimes, I eat breakfast [at } \\
\text { home] because I don't like ... } \\
\text { the things they serve at BIC.' }\end{array}$ \\
\hline Impacts & $\begin{array}{l}\text { 'I haven’t seen a student up here } \\
\text { in the office because his } \\
\text { stomach hurts ... since BIC } \\
\text { started ... they're all, you know, } \\
\text { eating in the morning. They’re } \\
\text { actually exercising their bodies, } \\
\text { possibly getting an appetite for } \\
\text { their lunch, so you're seeing } \\
\text { some value there as well too.' }\end{array}$ & $\begin{array}{l}\text { 'The children are eating. They're } \\
\text { getting that balanced meal in } \\
\text { the morning ... Because kids will } \\
\text { walk by before [when it was } \\
\text { served in the cafeteria], and, } \\
\text { you know, if they didn't see their } \\
\text { friend out there, they would just } \\
\text { go. Or if they were running late } \\
\text {... they didn't get to eat. And } \\
\text { [now] they're eating. And, you } \\
\text { know, even if it's a glass of milk } \\
\text { that they're getting, or some } \\
\text { fruit, they're putting something, } \\
\text { something in it. Some type of } \\
\text { vitamin that's going in their body } \\
\text { in the morning.' }\end{array}$ & $\begin{array}{l}\text { '[We pretend the class is a] café } \\
\text { and when they walk through the } \\
\text { door, they keep their voices } \\
\text { down, because we don't talk } \\
\text { really loud in restaurants, and } \\
\text { put your napkin on your lap. I } \\
\text { was trying to do more of like a } \\
\text { manners, table manners, that } \\
\text { kind of thing. But you know, I } \\
\text { mean, it cuts into our } \\
\text { instructional time, so little by } \\
\text { little, we've kind of stopped } \\
\text { doing certain instructional } \\
\text { things.' }\end{array}$ & $\begin{array}{l}\text { 'Sometimes, my son asks us - if } \\
\text { he likes whatever is available in } \\
\text { breakfast, he goes, "Mom, can } \\
\text { we find some - can we find this } \\
\text { at the market?" Because he } \\
\text { likes it. It's good. It's healthier. } \\
\text { "Mom, I never tried this before." } \\
\text { And, "Mom, can we go find - } \\
\text { and see if it's in the market?". }\end{array}$ & $\mathrm{N} / \mathrm{A}$ \\
\hline
\end{tabular}

N/A, not applicable. 


\section{Parents}

Parents generally appreciated and supported BIC, although they were concerned that the delivery model increased the burden on teachers. They recognized the challenges faced by families in getting their children to school early for breakfast when offered under the traditional SBP model and that BIC alleviated this challenge. Like school staff, some parents also believed that BIC offered students an opportunity to have more informal time within the school day that supported the development of relationships with their classroom peers. They also viewed the more highly supervised, safer environment in which students were now able to eat breakfast as an advantage. Parents appreciated that BIC relieved the pressure of ensuring that their children had eaten a full and balanced breakfast at home prior to leaving for school. Some indicated that their children were not hungry before school, or that morning routines at home did not consistently support the provision of a full breakfast.

\section{Students}

Students perceived BIC as having a relative advantage over the traditional delivery model of SBP for a variety of reasons, primarily because they perceived it as an opportunity to interact with their classmates more casually and in an emotionally and physically safer environment since interactions among children were restricted to fewer, same-aged peers. Secondarily, the timing of BIC seemed better aligned with students' hunger patterns and physical activity proclivity. In this regard, many students mentioned that they were often not hungry before school when the traditional SBP was offered and that they appreciated the opportunity to engage in free play during the before-school time previously used for the traditional SBP.

\section{Theme 3: consumption of Breakfast in the Classroom food}

The third theme encompassed perceptions about the BIC food that students consumed, including incompatibility of some of the foods with child preferences as well as incompatibility with parental values related to their role in feeding.

School staff (teachers, principals, food-service personnel) Many of the school staff believed that students choose whether to consume BIC food based on its perceived palatability rather than hunger, and attributed daily and inter-student variation in BIC food consumption to food preferences. Staff believed that many students consume breakfast prior to school and saw this 'double breakfast' as a potential source of excess energy, but also recognized that what students consume at home may not be nutritionally balanced or adequate.

\section{Parents}

Like school staff, parents perceived that children make decisions about whether to consume BIC food daily based on the published menu. Although parents reported that BIC reduces pressure to feed their children a substantial meal before school, they also indicated that they continue to provide at least some breakfast at home. This reported behaviour, which parents associated with a sense of responsibility and lack of clarity regarding their child's actual consumption of BIC foods, results in double breakfasts. However, some parents indicated that they fed their children less than they would or had in the absence of BIC. Many parents reported that they and their children decide together what and how much the student should consume before school based on the published menu.

\section{Students}

Students acknowledged that food preferences drive their BIC breakfast consumption patterns. Many students recounted previewing the published menu at home to determine whether to eat the BIC breakfast or to eat breakfast at home the next day. They also recalled choosing whether or not to eat the BIC breakfast after arriving at school and assessing the palatability of the food offered.

\section{Theme 4: perceived impacts of Breakfast in the Classroom}

The final theme encompassed respondents' perceptions about the BIC model's impacts on school finances, staffing and schedule, home and classroom routines, and food waste, as well as perceptions about the nutritional value of the BIC foods. These impacts represent perceived costs, relative advantages, and compatibility with the school environment and with existing values.

School staff (teachers, principals, food-service personnel) A number of school staff members were aware that federal reimbursement funds had increased because of BIC, resulting in additional discretionary funds for the district, and this was cited as a positive impact of BIC. Another subtheme was related to adjustments in the school schedule that were made to accommodate the programme. In some cases, school staff experienced the changes as disadvantageous since they were disruptive, while in other cases the changes were seen as a relative advantage. For example, for some schools, implementing BIC allowed school grounds to open later, permitting resources traditionally allocated to before-school supervision in the cafeteria to be reallocated.

Another subtheme that emerged was around the perceived impact of BIC on the amount of food waste generated, an area explored more extensively in a separate analysis ${ }^{(38)}$. Briefly, school staff indicated that total food waste had increased since children's 
preferences did not always align with the food served or children were satiated with smaller amounts of food than was served. Additionally, the short duration of the breakfast, food-service policies and programme coordination practices were perceived as contributors to waste.

The delivery model initially necessitated and supported additional food-service staff, which in many cases were provided by the district and viewed as a benefit to the school. School staff also mentioned that BIC provided a new means to engage parents: some parents who did not feel that they had a role in the school previously were now able to contribute by volunteering to assist with BIC in the younger grades. As indicated, school staff remained concerned about the potential impact on children's learning due to the foregone instructional time. However, they also noted heterogeneity in teacher practices during BIC, suggesting that the extent of this as a relative disadvantage may be variable. School staff also perceived the BIC time as rushed and some were concerned that children may not have adequate time to eat. With regard to the perceived nutritional impact, there was also a general lack of accurate awareness across school staff groups of the nutritional standards that food items are required to meet. Teachers, specifically, had mixed views about the nutritional quality of the breakfasts. Some viewed them as healthy and balanced, while others disagreed and perceived them as containing too much sugar and other carbohydrates.

\section{Parents}

Parents perceived several positive impacts of BIC. They reported that their children were willing to try foods that they may not have otherwise tried at home due to exposure and/or peer influence. Consequently, they believed the BIC delivery model has the potential to help normalize new and healthy foods. Some parents also reported that the delivery model helps shyer students build self-esteem, since they are no longer positioned to eat breakfast alone or with strangers. In terms of negative impacts, like school staff, parents remained concerned about the potential loss of instructional time and the need to rush through breakfast. They also had mixed views about the nutritional quality of the breakfasts. Like teachers, some believed that the breakfasts were healthy and balanced; while others believed that they were comprised of too much sugar. Parents generally lacked an accurate understanding of the US Department of Agriculture requirements guiding the nutrient content of the breakfasts. They expressed a desire to be more engaged in the BIC efforts and to have the opportunity to observe BIC first-hand to better understand their own child's BIC-related consumption patterns.

Minor themes expressed by school staff and parents Other themes emerged related to the impacts of BIC. School staff and parents perceived BIC as having a relative advantage over the traditional SBP in terms of addressing child hunger more comprehensively. They cited a number of observable effects such as improved attendance, fewer nurse visits due to stomach aches, improved energy throughout the school day, improved focus during instructional time and improved classroom cohesiveness. However, there seemed to be a mixed perception about the delivery model's impact on tardiness rates.

\section{Discussion}

The BIC model of SBP has the potential to be a large-scale and practical method of improving child nutrition and well-being, if implemented appropriately. In the present study we were able to capitalize on the opportunity to collect perceptions from multiple stakeholders in a district where BIC had recently been implemented. Collecting short-term retrospective perceptions in the midst of a district transition enabled a richer and more dynamic perspective.

Initial resistance to BIC model adoption may be grounded in some of the realities of the model or may reflect a more general resistance to change itself. Regardless, any opposition that arises presents an opportunity for school districts to engage stakeholders prior to implementation to improve model transition and implementation efforts. In fact, early engagement of stakeholders has been found to be a successful strategy in facilitating programme adoption ${ }^{(39)}$. Through the lens of the Diffusion of Innovations model, these results have a number of practical implications. Many teachers and school staff were able to articulate ways in which they had overcome initial concerns, suggesting that personnel in schools new to BIC could benefit from learning about the relative advantages experienced by other schools and teachers. One such advantage was the potential to provide novel opportunities for schools to engage and involve parents. In fact, parents and school staff appreciated these new ways for parents to volunteer at schools to support their BIC delivery models, and parents requested additional opportunities to engage and to obtain information about their children's consumption patterns.

The loss of instructional time resulting from moving the SBP from the cafeteria prior to school into the classroom after the bell remained a perceived relative disadvantage after the initial implementation period. Given the time frame of the study, positive effects on student long-term achievement would not yet be observable. However, of two studies conducted to date that compared student achievement between schools with BIC or traditional SBP models, one found no effect on test scores ${ }^{(30)}$ while the other found a beneficial effect, particularly for the most at-need student populations ${ }^{(40)}$. Further research is necessary to assess the impact of the reduction in instructional time on learning. If BIC has a positive or null 
impact on achievement, it will be important to preemptively address speculation to the contrary. It may likewise be important to allay initial concerns about the cost of the BIC innovation, particularly those related to expanded teacher roles. Overall, findings suggest that the additional investment was perceived as manageable and outweighed by the relative advantages of BIC.

There were a number of issues related to compatibility with culture, preferences and existing practices that could be addressed. For example, a prevailing parental value was the responsibility to feed their children before school. They viewed BIC as a supplementary rather than primary meal, a perspective that may result in students consuming more than one breakfast. More fully informing parents of the model's intent and allowing them to observe BIC implementation may shift their perception and reduce the occurrence of double breakfast. Comprehensive and effective communication of the nutrient value of the BIC meals to both parents and school staff may also reduce the occurrence of double breakfast and improve support for the model. It was noted by all stakeholder groups that some of the foods served were incompatible with child preferences. Districts considering adoption of BIC should consider investing in recipe and menu development prior to implementation. Finally, results from the current study suggest that perceptions about the compatibility of BIC with school routines and workflow evolved and that the BIC model integrated into organizational practices relatively rapidly.

\section{Suggestions for future related research}

Many of the perceived impacts expressed by school staff and parents have not been sufficiently studied. Additional research is needed to understand the role of BIC in promoting classroom cohesion and peer relationships and school culture more generally, as well as the impact on academic outcomes. Given the heterogeneity in teacher practices during BIC, it will be important to determine which are most beneficial to student learning. There is some research suggesting that double breakfasts associated with BIC do not increase overall energy intake and have a positive effect on diet quality; however, more research is needed to confirm these findings ${ }^{(32)}$. Finally, quantitative studies are needed that expand or validate these qualitative findings.

\section{Strengths and limitations}

A major strength of the present study was the ability to collect perceptions from stakeholders in a district where BIC had recently been implemented, enabling the capture of perspectives on the transition in real time. The study captured a richness of perspectives by including multiple stakeholders and both English- and Spanish-speaking parents. Finally, the study is timely in terms of its relevance to trends in BIC expansion nationwide.
While the present study provides new insights into the varied perceptions of the BIC model of SBP, there are several limitations. The study, conducted in a large urban school district with a high percentage of students from low-income households, may not be generalizable to other settings. Second, there were several potential sources of selection bias. The involvement of district leadership in recruitment of participating schools may have resulted in a sample that was more favourable towards the model. The sample of parents and teachers who chose to participate in the focus groups may have differed from those who chose not to participate. The sample was predominantly female; therefore male stakeholders and their views were under-represented, particularly male teachers, parents and cafeteria managers. However, based on a review of the data disaggregated by gender, it does not appear that male perceptions are substantially different from those represented here.

\section{Conclusion}

The present qualitative study provides rich insight into key stakeholders' perceptions of BIC, a specific delivery model of a US federally funded school meals programme that is being adopted by an increasing number of school districts across the country. Results indicate that pre-emptively considering issues related to cost, relative advantage, compatibility and observability, and engaging parents and school communities prior to and during BIC adoption, could foster successful implementation, thereby addressing child hunger and nutrition needs particularly relevant to schools with high proportions of students from lowincome households. These findings provide policy makers, districts and practitioners with new information that can be used to improve BIC implementation, delivery, participation and outcomes.

\section{Acknowledgements}

Acknowledgements: The authors would like to thank the following individuals for their involvement in the project: Su Pak, Hayden Ross, Emily Rak, Stephanie Anzman-Frasca, Allison Knott, Nicole Lanoue, Vanessa Lynskey, Firas Shalabi and Shanti Sharma. Additionally, they would thank the school district staff and study participants for their contributions. Financial support: This study was conducted by ChildObesity 180 at Tufts University. Strategic funding for ChildObesity180 is provided by the Robert Wood Johnson Foundation (grant number 70230) and The JPB Foundation. S.A.B.'s contribution to this work was supported by the National Institute of Food and Agriculture, US Department of Agriculture (agreement number 2012-38420-30200). The funders had no role in the design, analysis or writing of 
this article. Conflict of interest: The authors declare no conflict of interest. Authorship: All authors contributed to the manuscript development. S.C.F. led study design and manuscript finalization and contributed to data analysis and manuscript development. H.C.D. contributed to design and data collection, led data analysis, and led manuscript development. M.H. contributed to study design and led data collection. N.M. contributed to study design, data collection and data analysis. S.A.B. contributed to study design and data analysis. K.S.S. contributed to study design, data collection and data analysis. C.D.E. served as principal investigator and oversaw all stages of study design, data collection, data analysis and manuscript development. Ethics of buman subject participation: The study was conducted according to the Declaration of Helsinki and all procedures involving human subjects were approved by the Tufts University Institutional Review Board. Tufts researchers also followed usual protocol for conducting research in the district, including obtaining approval from district's research office. Written or verbal informed consent or assent was obtained from all participants. Verbal consent or assent was witnessed and formally recorded.

\section{References}

1. Chitra U \& Reddy CR (2007) The role of breakfast in nutrient intake of urban schoolchildren. Public Health Nutr 10, $55-58$.

2. Rampersaud GC (2009) Benefits of breakfast for children and adolescents: update and recommendations for practitioners. Am J Lifestyle Med 3, 86-103.

3. Deshmukh-Taskar PR, Nicklas TA, O'Neil CE et al. (2010) The relationship of breakfast skipping and type of breakfast consumption with nutrient intake and weight status in children and adolescents: the National Health and Nutrition Examination Survey 1999-2006. J Am Diet Assoc 110, 869-878.

4. Sandercock GR, Voss C \& Dye L (2010) Associations between habitual school-day breakfast consumption, body mass index, physical activity and cardiorespiratory fitness in English schoolchildren. Eur J Clin Nutr 64, 1086-1092.

5. Schembre SM, Wen CK, Davis JN et al. (2013) Eating breakfast more frequently is cross-sectionally associated with greater physical activity and lower levels of adiposity in overweight Latina and African American girls. Am J Clin Nutr 98, 275-281.

6. Baharudin A, Zainuddin AA, Manickam MA et al. (2014) Factors associated with physical inactivity among schoolgoing adolescents: data from the Malaysian School-Based Nutrition Survey 2012. Asia Pac J Public Health 26, 5 Suppl., 27S-35S.

7. Adolphus K, Lawton CL \& Dye L (2013) The effects of breakfast on behavior and academic performance in children and adolescents. Front Hum Neurosci 7, 425.

8. Rampersaud GC, Pereira MA, Girard BL et al. (2005) Breakfast habits, nutritional status, body weight, and academic performance in children and adolescents. $J$ Am Diet Assoc 105, 743-760.

9. Hoyland A, Dye L \& Lawton CL (2009) A systematic review of the effect of breakfast on the cognitive performance of children and adolescents. Nutr Res Rev 22, 220-243.
10. Szajewska H \& Ruszczynski M (2010) Systematic review demonstrating that breakfast consumption influences body weight outcomes in children and adolescents in Europe. Crit Rev Food Sci Nutr 50, 113-119.

11. Horikawa C, Kodama S, Yachi Y et al. (2011) Skipping breakfast and prevalence of overweight and obesity in Asian and Pacific regions: a meta-analysis. Prev Med 53, 260-267.

12. US Department of Agriculture, Food and Nutrition Service (2014) School Breakfast Program (SBP): Program History. http://www.fns.usda.gov/sbp/program-history (accessed September 2015)

13. Bhattacharya J, Currie J \& Haider SJ (2006) Breakfast of champions? The School Breakfast Program and the nutrition of children and families. J Hum Res 41, 445-466.

14. Clark MA \& Fox MK (2009) Nutritional quality of the diets of US public school children and the role of the school meal programs. J Am Diet Assoc 109, 2 Suppl., S44-S56.

15. Gleason P, Briefel R, Wilson A et al. (2009) School Meal Program Participation and Its Association with Dietary Patterns and Childhood Obesity. Final Report. Washington, DC: US Department of Agriculture.

16. Affenito SG, Thompson D, Dorazio A et al. (2013) Readyto-eat cereal consumption and the School Breakfast Program: relationship to nutrient intake and weight. $J$ Sch Health 83, 28-35.

17. Gleason PM \& Dodd AH (2009) School breakfast program but not school lunch program participation is associated with lower body mass index. J Am Diet Assoc 109, 2 Suppl., S118-S128.

18. US Department of Agriculture, Food and Nutrition Service, Office of Research and Analysis (2012) School Nutrition Dietary Assessment Study IV. Alexandria, VA: US Department of Agriculture, Food and Nutrition Service.

19. US Department of Agriculture, Food and Nutrition Service (2014) School Breakfast Program Fact Sheet. http://www. fns.usda.gov/sites/default/files/SBPfactsheet.pdf (accessed September 2015).

20. Bailey-Davis L, Virus A, McCoy TA et al. (2013) Middle school student and parent perceptions of government-sponsored free school breakfast and consumption: a qualitative inquiry in an urban setting. J Acad Nutr Diet 113, 251-257.

21. McDonnell E, Probart C, Weirich JE et al. (2004) School breakfast programs: perceptions and barriers. J Child Nutr Manage issue 2, Fall 2004; available at http://docs.schoolnutrition.org/newsroom/jcnm/04fall/mcdonnell/index.asp

22. Basch CE (2011) Breakfast and the achievement gap among urban minority youth. J Sch Health 81, 635-640.

23. Food Research and Action Center (2015) School Breakfast Scorecard: School Year 2013-2014. Washington, DC: FRAC.

24. Share Our Strength (2013) Breakfast Changes Lives Ensuring No Kids Goes Hungry in the Classroom: Share Our Strength's Breakfast Report 2013. Washington, DC: Share Our Strength.

25. Fuel Up to Play 60 (2014) Expanding Breakfast. https:// dashboard.futpforms.com/tools/nutrition-education/view. php?id=23965654 (accessed January 2016).

26. School Nutrition Association (2015) School Nutrition Trends \& Stats. https://schoolnutrition.org/AboutSchoolMeals/ SchoolMealTrendsStats/ (accessed September 2015).

27. McLaughlin J, Bernstein L, Crepinsek M et al. (2002) Evaluation of the School Breakfast Program Pilot Project: Findings from the First Year of Implementation. Nutrition Assistance Program Report Series no. CN-02-SBP. Alexandia, VA: US Department of Agriculture, Food and Nutrition Service, Office of Analysis, Nutrition, and Evaluation.

28. Nanney MS, Olaleye TM, Wang Q et al. (2011) A pilot study to expand the school breakfast program in one middle school. Transl Behav Med 1, 436-442. 
29. Food Research and Action Center (2012) School Breakfast in America's Big Cities: School Year 2010-2011. Washington, DC: FRAC.

30. Anzman-Frasca S, Djang H, Halmo MM et al. (2015) Estimating impacts of a breakfast in the classroom program on school outcomes. JAMA Pediatr 169, 71-77.

31. Van Wye G, Seoh H, Adjoian T et al. (2013) Evaluation of the New York City breakfast in the classroom program. $A m J$ Public Health 103, e59-e64.

32. Ritchie LD, Rosen NJ, Fenton K et al. (2015) School breakfast policy is associated with dietary intake of fourth- and fifth-grade students. J Acad Nutr Diet (Epublication ahead of print version).

33. Huang H-C, Lee K-I \& Shanklin C (2006) Evaluation of the free school breakfast program in St. Joseph, Missouri. J Child Nutr Manage issue 1, Spring 2006; available at http://docs.schoolnutrition.org/newsroom/jcnm/06spring/ huang/index.asp

34. Lambooij MS \& Hummel MJ (2013) Differentiating innovation priorities among stakeholder in hospital care. BMC Med Inform Decis Mak 13, 91.
35. Miles MB, Huberman AM \& Saldana J (2013) Qualitative Data Analysis: A Methods Sourcebook. Thousand Oaks, CA: SAGE Publications Inc.

36. Rogers EM (2003) Diffusion of Innovations, 5th ed. New York: Free Press.

37. Brownson RC, Tabak RG, Stamatakis KA et al. (2015) Implementation, dissemination, and diffusion of public health interventions. In Health Behavior: Theory, Research, and Practice, 5th ed., pp. 301-325 [K Glanz, B Rimer and K Viswanath, editors]. San Francisco, CA: Jossey-Bass.

38. Blondin SA, Djang HC, Metayer N et al. (2015) 'It's just so much waste.' A qualitative exploration of food waste in a universal free School Breakfast Program. Public Health Nutr 18, 1565-1577.

39. Creighton L (2012) Stakeholder engagement for successful breakfast in the classroom implementation. J Sch Health $\mathbf{8 2}$, 496-498.

40. Imberman SA \& Kugler AD (2014) The effect of providing breakfast in the class on student performance. J Policy Anal Manage 33, 669-699. 